\title{
COVID-19 and liver surgery in France, Italy, Japan, and the United States: A report of a single topic conference of Eastern and Western Association for Liver Tumors (EWALT) 2021
}

\author{
Kyoji Ito', Nobuyuki Takemura' ${ }^{1}$ Kiyoshi Hasegawa ${ }^{2}$, Norihiro Kokudo ${ }^{1, *}$ \\ ${ }^{1}$ National Center for Global Health and Medicine, Tokyo, Japan; \\ ${ }^{2}$ Hepato-Biliary-Pancreatic Surgery Division, Artificial Organ and Transplantation Division, Department of Surgery, Graduate School of \\ Medicine, The University of Tokyo, Tokyo, Japan.
}

\begin{abstract}
The Eastern and Western Association for Liver Tumors (EWALT) is an international association for clinical and basic scientists dedicated to worldwide study on hepatocellular carcinoma. A single topic conference of EWALT on "COVID-19 and Liver Surgery" was held online on April 23th, 2021. The presenters from France, Italy, Japan, and the United States, reported the current situation of COVID-19 in each country and the influence on the clinical practice and education in hepato-pancreato-biliary surgery. Here we would like to summarize the core of this single topic conference.
\end{abstract}

Keywords: COVID-19, liver surgery, HPB surgery, EWALT

The Eastern and Western Association for Liver Tumors (EWALT) is an international association for clinical and basic scientists dedicated to worldwide study on hepatocellular carcinoma. A single topic conference of EWALT on "COVID-19 and Liver Surgery" was held online on April 23th, 2021.

Opening remarks by Prof. Norihiro Kokudo, the chairperson of the EWALT 2021 single topic conference, declared the conference open and presented the conference agenda. After briefly touching on the history of EWALT, he expressed his regret that the usual EWALT congress for 2021 had been postponed. Instead of the usual conference, a single topic conference was held online to discuss the theme, "COVID-19 and Liver Surgery". Prof. Kokudo remarked that he was pleased with the large number of participants from numerous countries (163 participants from 21 countries) who registered for the conference. In addition, the upcoming EWALT congress, re-scheduled for February 2022, was announced.

A video message from Prof. Masatoshi Makuuchi, a co-organizer of the first EWALT conference, was broadcast. He thanked the participants for attending the conference and hoped that the discussion of "COVID-19 and Liver Surgery" during the conference would contribute to the fight against COVID-19 in countries around the world. He also expressed his hopes of seeing participants in person at the next conference in February 2022.
As the Keynote lecture, Prof. René Adam, the president of the Medical Board of the Paul Brousse Hospital, reported the results of international surveys and studies on surgery during the COVID-19 pandemic (Figure 1). An online survey conducted by the EuropeanAfrican Hepato-Pancreato-Biliary Association (E-AHPBA) Scientific \& Research Committee during the first wave of COVID-19 revealed that most medical facilities experienced limited use of operating rooms, a delay in cancer surgery, and cancelation of non-essential surgery; this was especially true in countries with a higher incidence of COVID-19 (1). Another survey, based on the IHPBA-COVID Registry, reported that COVID-19 was associated with a high mortality rate after hepato-pancreato-biliary (HPB) surgery (29\% for pancreaticoduodenectomy, $15 \%$ major hepatectomy, and $3 \%$ cholecystectomy). Lastly, Prof. Adam described a study conducted by Khonsari et al. regarding the effects of the COVID-19 pandemic on surgical outcomes (2). The study found that the incubation period, a recent history of infection, and a potential nosocomial infection were associated with pulmonary complications and mortality. Prof. Adam described how several studies on liver transplantation reported a higher risk of COVID-19 in transplant candidates and a higher COVID-19related mortality in candidates and recipients (3). $\mathrm{He}$ concluded that COVID-19 screening with $\mathrm{PCR} \pm \mathrm{CT}$ was recommended for all patients undergoing HPB surgery and liver transplantation and that positivity for 
(A)

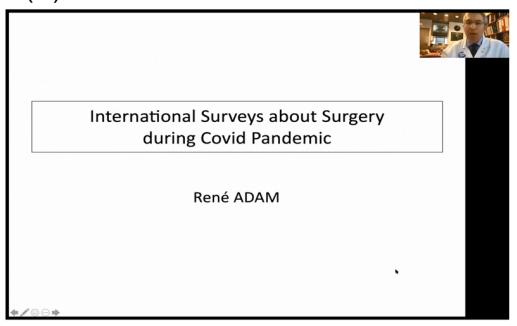

(C)

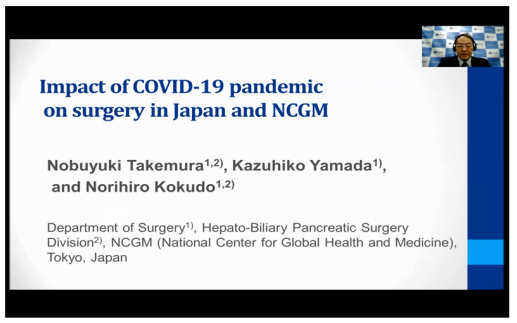

(B)

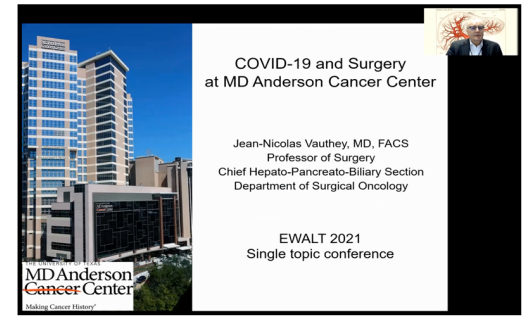

(D)

(E)

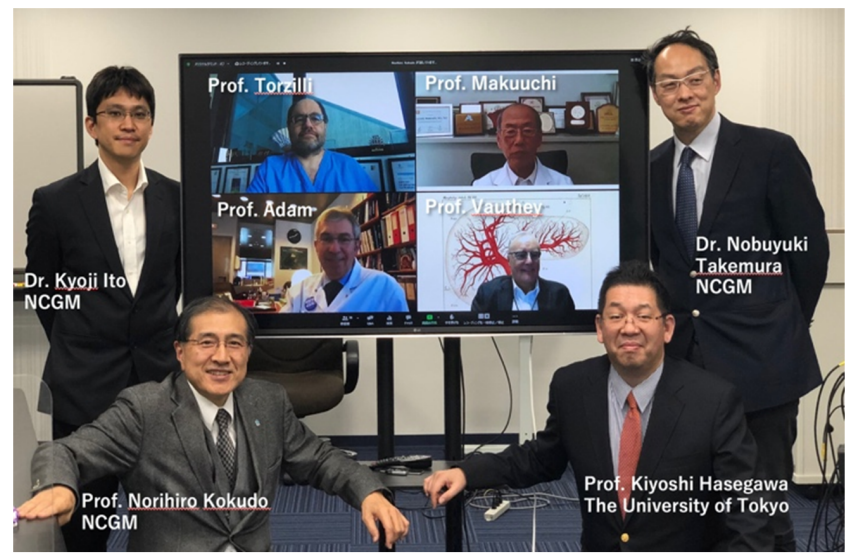

Figure 1. Presentation in the keynote lecture and panel session. Keynote lecture from René Adam (A), panel speech from Jean-Nicolas Vauthey (B), Nobuyuki Takemura (C), Guido Torzilli (D), and the group photo (E).

COVID-19 would be a contraindication for HPB surgery and liver transplantation.

The Panel Session was moderated by Prof. Norihiro Kokudo and Prof. Kiyoshi Hasegawa. In this session, Prof. Jean-Nicolas Vauthey from the MD Anderson Cancer Center described COVID-19 trends in the United States and Texas. Over 30 million people were confirmed to have COVID-19, and over 5.51 million died from COVID-19. Indeed, COVID-19 became the 3rd leading cause of death in 2020 after cardiovascular disease and cancer. However, the situation has improved as vaccination rates have increased, with the US having a rate of $38 \%$ and Texas having a rate of $34 \%$. Prof. Vauthey then described the institutional response to COVID-19 at the MD Anderson Cancer Center, including visitor restrictions, temperature screening at all entrances, travel bans and virtual meetings for all employees, COVID-19 testing before surgery, demarcation of floors based on their COVID-19 status, and promotion of telemedicine. As a result, the risk of COVID-19 after surgery was extremely low, with a risk of $0.46 \%$ for inpatients undergoing surgery overall and $0.51 \%$ for patients undergoing HPB surgery (4). In addition, he presented a case-matched analysis of postoperative morbidity comparing a group that recovered from COVID-19 and a control group. The group that recovered from COVID-19 was given a minimal wait time after recovery of 20 days, and there were no differences in postoperative morbidity between the groups, suggesting the safety and feasibility of surgery for patients who had recovered from COVID-19. Lastly, he mentioned several difficulties with training surgical fellows during the COVID-19 pandemic. He also described how the MD Anderson Cancer Center had implemented several measures with a three-pronged focus (clinical, didactics, and research).

Prof. Nobuyuki Takemura from the National Center for Global Health and Medicine (NCGM) described the status of the COVID-19 pandemic in Japan and institutional policies to combat COVID-19. Japan witnessed three spikes in COVID-19 and was experiencing the 4 th spike in the spring, but the vaccination rate was still only $1 \%$. To reduce the risk of infection among medical workers and patients, a 
PCR test and screening were mandated for all surgical candidates. As a result, only 5 of 2,348 patients $(0.2 \%)$ tested positive for COVID-19 after surgery. He mentioned other measures adopted at the NCGM, including expansion of dedicated COVID-19 wards, reconfiguration of the intensive care unit into a negativeair-pressure room, and demarcation of operating rooms based on COVID-19 status. He also described the results of a survey on the impact of COVID-19 on surgery. Seventeen hospitals responded to the survey. Ten hospitals $(60 \%)$ limited elective surgery during the waves of COVID-19, and some surgeries were delayed or cancelled. Lastly, he mentioned several difficulties with surgical training for younger surgeons since fewer surgeries were performed during the COVID-19 pandemic.

Prof. Guido Torzilli from Humanitas University explained the status of the COVID-19 pandemic in Italy. Italy has experienced three waves of COVID-19 thus far, and the waves have been accompanied by a high rate of hospital bed use and ICU bed displacement. At his hospital, 53 cases of COVID-19 were reported among healthcare professionals, with $20.8 \%$ (11/53) involving surgeons (5). As a result, surgery at his hospital was restricted, and indeed, the number of liver surgeries and pancreatic surgeries in 2020 decreased by $32 \%$ and $13 \%$, respectively, compared to numbers in 2019 . In addition, a decrease in outpatients and a shortage of blood components occurred during the waves of COVID-19, which also resulted in fewer surgeries (6). Prof. Torzilli also described the framework adopted by the Italian Society of Surgical Oncology to cope with the situation, which included prioritization of surgery, protection of central hospitals, a regionally even distribution of surgery, dedicated paths and logistics, and promotion of telemedicine (7). Lastly, he mentioned the vaccination rate in Italy. The rate of vaccination with the $1^{\text {st }}$ dose was $20 \%$ and that with the $2^{\text {nd }}$ dose was $8 \%$. The current 3rd wave of COVID-19 has been abating as the vaccination rate has increased.

Prof. Kiyoshi Hasegawa from the University of Tokyo, the co-chairperson of the EWALT 2021 single topic conference, delivered the closing remarks. Prof. Hasegawa thanked the speakers and participants. He also mentioned the upcoming EWALT conference, scheduled for February 2022. The regular conference will be held at Ito Hall at the University of Tokyo. Calls for registration and abstract submission were announced.

\section{Acknowledgements}

The authors would like to thank Masatoshi Makuuchi, René Adam, Jean-Nicolas Vauthey, and Guido Torzilli for presenting the thoughtful lectures on COVID-19 and Hepato-Pancreato-Biliary Surgery in the conference.
Funding: None.

Conflict of Interest: The authors have no conflicts of interest to disclose.

\section{References}

1. Balakrishnan A, Lesurtel M, Siriwardena AK, et al. Delivery of hepato-pancreato-biliary surgery during the COVID-19 pandemic: an European-African HepatoPancreato-Biliary Association (E-AHPBA) cross-sectional survey. HPB (Oxford). 2020; 22:1128-1134.

2. Khonsari RH, Bernaux M, Vie JJ, Diallo A, Paris N, Luong LB, Assouad J, Paugam C, Simon T, Vicaut E, Nizard R, Vibert E; AP-HP/Universities/INSERM COVID-19 research collaboration, AP-HP COVID Clinical Data Warehouse initiative. Risks of early mortality and pulmonary complications following surgery in patients with COVID-19. Br J Surg. 2021; 108:e158-e159.

3. Polak WG, Fondevila C, Karam V, Adam R, Baumann U, Germani G, Nadalin S, Taimr P, Toso C, Troisi RI, Zieniewicz K, Belli LS, Duvoux C. Impact of COVID-19 on liver transplantation in Europe: alert from an early survey of European Liver and Intestine Transplantation Association and European Liver Transplant Registry. Transpl Int. 2020; 33:1244-1252.

4. Kothari AN, Trans AT, Caudle AS, Clemens MW, Katz MHG, Woodman SE, Chang GJ. Universal preoperative SARS-CoV-2 testing can facilitate safe surgical treatment during local COVID-19 surges. Br J Surg. 2021; 108:e24-e26.

5. Torzilli G, Famularo S, Azzolini E, Vespa E, Lleo A, Aghemo A, Lagioia M, Castoro C. Identifying medical professionals at risk for in-hospital COVID-19 infection: a snapshot during a "tsunami" highlighting unexpected risks. Glob Health Med. 2020; 2:235-239.

6. Torzilli G, Viganò L, Galvanin J, Castoro C, Quagliuolo V, Spinelli A, Zerbi A, Donadon M, Montorsi M; COVIDSURGE-ITA group. A snapshot of elective oncological surgery in Italy during COVID-19 emergency: pearls, pitfalls, and perspectives. Ann Surg. 2020; 272:e112-e117.

7. Spolverato G, Restivo A, Capelli G, De Luca R, Roviello F, D Ugo D, Delrio P, Garofalo A, Lorenzon L, Boggi U, Folli S, Torzilli G, Gronchi A; Italian Society of Surgical Oncology (Società Italiana di Chirurgia Oncologica, SICO). Cancer networks as a response to COVID pandemic: A framework from the Italian Society of Surgical Oncology. J Surg Oncol. 2021; 123:1201-1203.

Received May 30, 2021; Accepted June 25, 2021.

Released online in J-STAGE as advance publication July 5, 2021.

*Address correspondence to:

Norihiro Kokudo, National Centre for Global Health and Medicine, 1-21-1 Toyama, Shinjuku-ku, Tokyo 162-8655, Japan.

E-mail: nkokudo@hosp.ncgm.go.jp 